\title{
CHEMOSPHERE
}

\section{Polycyclic aromatic hydrocarbons in the surface soils from outskirts of Beijing, China}

\author{
L.L. Ma ${ }^{\text {a }}$, S.G. Chu ${ }^{\text {a }}$, X.T. Wang ${ }^{\text {a }}$, H.X. Cheng ${ }^{\text {b }}$, X.F. Liu ${ }^{\text {a }}$, X.B. Xu ${ }^{\text {a,* }}$ \\ ${ }^{a}$ Research Center for Eco-Environmental Sciences, Chinese Academy of Sciences, P.O. Box 2871, Beijing 100085, China \\ ${ }^{\mathrm{b}}$ Institute of Geochemical \& Geophysical Exploration, Beijing, 065000, China
}

Received 2 February 2004; received in revised form 8 September 2004; accepted 21 September 2004

\begin{abstract}
Surface soils from the outskirts of Beijing were analyzed for 16 priority polycyclic aromatic hydrocarbons (PAHs) using gas chromatography and mass spectrometry (GC-MS). The distribution map of total PAHs content was obtained as a contour plot. The concentration range of $16 \mathrm{PAHs}$ varied by over two orders of magnitude from $0.016 \mu \mathrm{g} \mathrm{g}^{-1}$ in rural to $3.884 \mu \mathrm{g} \mathrm{g}^{-1}$ in suburban soils with the relatively standard deviation of $70.5 \%$, showing large differences in the extent of PAHs pollution at the various sampling sites. It was notable that the concentration of $\mathrm{BaP}$ was $0.005-$ $0.270 \mu \mathrm{g} \mathrm{g}^{-1}$ with a mean of $0.055 \mu \mathrm{g} \mathrm{g}^{-1}$. In general, the distribution of PAHs centered on the high molecular weight PAHs known to be carcinogenic. The 4-6 ring PAHs represented about $66 \%$ in rural samples and $70 \%$ in suburban soils of the total PAHs found. There was relatively good relationship among most of the individual PAHs and the compounds of Pyr, BaA, Flu, BbF, BaP, Chr and Ph gave strong correlation $(r>0.8)$ with the sum of PAHs. The selected marked compounds, a principal component analysis (PCA) and special PAHs compound ratios ( $\mathrm{Ph} / \mathrm{An}$ vs Flu/Pyr; $\sum \mathrm{COMB} / \sum \mathrm{EPA}-\mathrm{PAHs}$ ) suggest the pyrogenic origins, especially traffic exhausts, are the dominant sources of PAHs in Beijing outskirts soils.
\end{abstract}

(C) 2004 Elsevier Ltd. All rights reserved.

Keywords: PAHs; Surface soils; Principal component analysis; Traffic emission; Beijing

\section{Introduction}

There is a globally increasing concern about environmental pollution by persistent organic pollutants (POPs). Besides 12 POPs listed in "Stockholm Convention", the polycyclic aromatic hydrocarbons (PAHs) were included among 16 POPs designated in "Convention of Long-range Transboundary Air Pollution"

\footnotetext{
* Corresponding author. Tel.: +8610629 19 177; fax: +86 10 62923563.

E-mail address: xuxb@public.bta.net.cn (X.B. Xu).
}

adopted by United Nations Economic Commission for Europe. PAHs are also identified as high priority chemicals in "Regionally-based assessment of Persistent Toxic Substances" in Region VII (including China) conducted by United Nations Environment Programme and Global Environmental Fund. As ubiquitous contaminants, PAHs are particularly harmful due to their carcinogenic and mutagenic properties (IARC, 1983; Perera, 1997). The US Environmental Protection Agency (EPA) has promulgated 16 unsubstituted PAHs (EPA-PAH) as priority pollutants. Eight PAHs (Car-PAHs) typically considered as possible carcinogens are: benz $(a)$ anthracene, chrysene, benzo(b)fluoranthene, benzo( $k$ )fluoranthene, 
benzo $(a)$ pyrene, $\operatorname{dibenz}(a, h)$ anthracene, indeno(1,2,3$c d$ )pyrene and benzo $(g, h, i)$ perylene (Menzie et al., 1992). Although natural sources affect the concentrations in local areas, PAHs occur primarily due to the anthropogenic inputs including the incomplete combustion or pyrolysis of organic material and the direct release of oil or its products. The previous investigations showed traffic was the major PAHs source in metropolitan areas (Rogge et al., 1993a; Van Metre et al., 2000; Okuda et al., 2002). Comparatively stable molecular structure, slow rates of photochemical decomposition and biodegradation contribute to the persistence of PAHs in the environment. Soil system seems to be the important long-term repository for PAHs and is considered to be a steady indicator of the environmental pollution state (Wild et al., 1990; Wild and Jones, 1995). Accumulation of PAHs in soils may lead to further potential contamination of vegetables and food chains (Meharg et al., 1998; Kipopoulou et al., 1999), and then cause direct or indirect exposure to human. Moreover, leaching, evaporation and migration are possible PAHs sources of atmospheric or groundwater contamination (Bispo et al., 1999; Cousins et al., 1999). Therefore, knowledge of soil contamination with PAHs is needed to avoid any food production risk and to restrict the deleterious effect of these contaminants. Many studies have been reported for the PAHs in soils in some countries (Edwards, 1983; Jones et al., 1989; Wilcke et al., 1999; Wilcke, 2000). However, in China most investigation only directed towards determining PAHs concentrations and distributions in water (Bi et al., 2001; Wang et al., 2004), air (Katagiri et al., 1996; Li et al., 2001) and sediment (Liu et al., 2000; Yang, 2000; Wu et al., 2003). Up to now, comparatively few investigations have been conducted to address the accumulation and distribution of PAHs in the soils (Chu et al., 2003; Wang et al., 2003; Tao et al., 2004).

Beijing $\left(39^{\circ} 48^{\prime} \mathrm{N}\right.$ and $\left.116^{\circ} 28^{\prime} \mathrm{E}\right)$, as the capital, is the second largest city in China. The high population (over 13 million) and rapid industrialization during the last decades have resulted in a lot of environmental problems. The vehicle in Beijing grows at a rate of $15 \%$ per year through the 1990s, and now exceeds 2.0 million ( $\mathrm{He}$ et al., 2001). The PAHs concentrations calculated in terms of total suspended particles were $178 \mu \mathrm{g} \mathrm{g}^{-1}$ in summer and $749 \mu \mathrm{g} \mathrm{g}^{-1}$ in winter (Okuda et al., 2002). The benzo( $a)$ pyrene concentration in outdoor air in residential areas of Beijing was approximately 15 times higher than that in residential areas around a main road of Tokyo (Katagiri et al., 1996). Therefore, it is urgent to investigate PAHs in the environment of Beijing. By now, scarce research concerned about PAHs in the Beijing soils (Chu et al., 2003; Ma et al., 2003).

In 2001, the Chinese government carried out an investigation to assess the state of soil contamination on the Beijing outskirts where are undergoing great changes due to the rapid urbanization and industrial development. This paper described here is part of the wider research project. In the present study, surface soils from Beijing rural and suburban areas were investigated to identify the current PAHs contamination status, composition and possible sources.

\section{Material and methods}

\subsection{Materials and reagents}

The standard solutions including 16 EPA-PAHs (naphthalene, $\mathrm{Na}$; acenaphthylene, Acy; acenaphthene, Ace; fluorene, Fl; phenanthrene, $\mathrm{Ph}$; anthracene, An; fluoranthene, Flu; pyrene, Pyr; benz $(a)$ anthracene, $\mathrm{BaA}$; chrysene, Chr; benzo $(b)$ fluoranthene, $\mathrm{BbF}$; benzo $(k)$ fluoranthene, $\mathrm{BkF}$; benzo $(a)$ pyrene, $\mathrm{BaP}$; indeno(1,2,3-cd)pyrene, InP; dibenz $(a, h)$ anthracene, DBA; benzo $(g, h, i)$ perylene, BghiP) each at the concentration of $1000 \mu \mathrm{g} \mathrm{ml}^{-1}$ were obtained from Supelco (Bellefonte, PA, USA). 2-flurobiphenyl was purchased from Aldrich chemical company. The standards were further diluted with isooctane to prepare working standards. Silica gel (100-200 mesh; Qingdao Haiyang Chemical Company, China) was activated at $130{ }^{\circ} \mathrm{C}$ for $12 \mathrm{~h}$. All the solvents (Beijing Chemical Factory, China) were of analytical purity and redistilled in all-glass system prior to use.

\subsection{Sampling and preparation}

Surface soil samples at the depth about $5-30 \mathrm{~cm}$ were collected covering an areas of about $1000 \mathrm{~km}^{2}$ in April 2001 and the sampling sites are shown in Fig. 1. Samples 1-14 were from rural area and samples 15-47 were from suburban area.

Firstly, multiple cores covering about $1 \mathrm{~km}^{2}$ were collected to get one subsample with stainless steel drill and then 16 vicinal subsamples were mixed fully to obtain one pooled sample representing $16 \mathrm{~km}^{2}$ areas. The soil was air-drying in fume hood at room temperature, sieved to $<1 \mathrm{~mm}$ and stored in glass bottles at $-4{ }^{\circ} \mathrm{C}$. The remaining water content in the soil was determined gravimetrically after drying individual sample in an oven at $105^{\circ} \mathrm{C}$ for $12 \mathrm{~h}$. All results were reported as dried weight basis.

\subsection{Sample extraction and clean-up}

After $1 \mathrm{ml}$ of 2-flurobiphenyl $\left(4.0 \mu \mathrm{g} \mathrm{ml}^{-1}\right)$ added as surrogate, accurately weighed soil (about $5 \mathrm{~g}$ ) was extracted by ultrasonic in $30 \mathrm{ml}$ acetone/petroleum ether (1/1) thrice during $15 \mathrm{~min}$ followed and separated by centrifugation. The solvent was evaporated by K-D apparatus and then reduced to about $1 \mathrm{ml}$ by a gentle stream of nitrogen. 


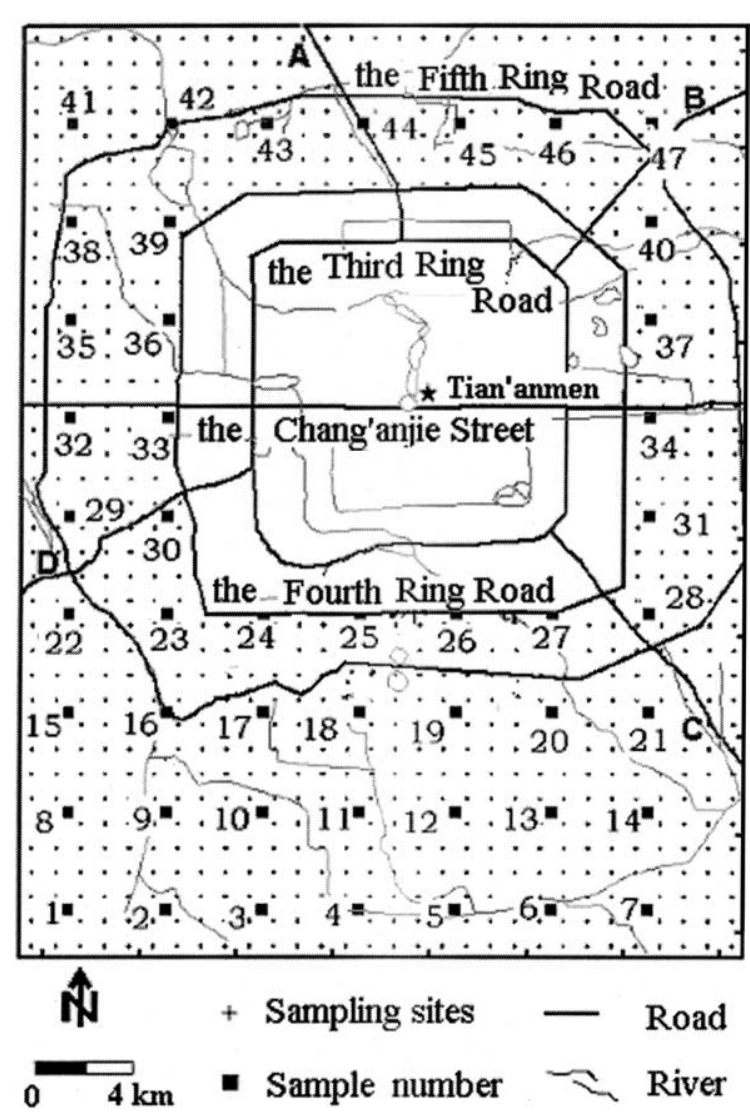

Fig. 1. Map of sampling sites on the outskirts of Beijing, China. A, B, C and D are four main highways.

The concentrated extract was fractioned with a silica gel column $(30 \mathrm{~cm} \times 10 \mathrm{~mm}$ i.d.) packed with $10 \mathrm{~g}$ of silica gel (pre-soaked in dichloromethane), which was preeluted with $40 \mathrm{ml}$ of petroleum ether before loading the sample. After the sample was transferred onto the column, it was firstly eluted with $25 \mathrm{ml}$ of petroleum ether and secondly eluted with $30 \mathrm{ml}$ of petroleum ether/ dichloromethane (3/2). The first fraction contained aliphatic hydrocarbons and the second fraction contained PAHs. Solvent in each fraction was evaporated by K-D apparatus and then reduced the volume to $0.2 \mathrm{ml}$ by a gentle stream of nitrogen for determination.

\subsection{PAHs determination}

The determination of PAHs was performed on a Hewlett Parkard 6890 gas chromatography-5973 mass selective detector (GC-MS) system equipped with a fused silica capillary DB-5 column $(30 \mathrm{~m} \times 0.25 \mathrm{~mm}$ i.d., $0.25 \mu \mathrm{m}$ film thickness). The carrier gas was helium. The ionization was carried out in the electron impact mode at $70 \mathrm{eV}$ and the mass range scanned was from 50 to $550 \mathrm{amu}$ under full scan acquisition mode. The temperature program was as follows: initial temperature of $50{ }^{\circ} \mathrm{C}$ was held for $2 \mathrm{~min}$, increased at a rate of $4{ }^{\circ} \mathrm{C}$ $\min ^{-1}$ to $280^{\circ} \mathrm{C}$, then held for $20 \mathrm{~min} .1 \mu$ volume of each sample was injected in the splitless mode and the purge time was $1 \mathrm{~min}$. Identification of the compounds was based on the comparison of their GC-retention times and mass spectrum with appropriate individual standards.

The limits of detection (LODs) calculated with a signal-to-noise ratio of $3: 1$ in blank sample $(n=5)$ ranged from $0.002 \mu \mathrm{g} \mathrm{g}^{-1}$ for $\mathrm{BaA}$ to $0.042 \mu \mathrm{g} \mathrm{g}^{-1}$ for $\mathrm{Na}$. The average recoveries $(n=5)$ with spiked PAHs $\left(4.0 \mu \mathrm{g} \mathrm{ml}^{-1}\right)$ in soil ranged from $75 \%$ to $120 \%$. The relative standard deviations were less than $5 \%$. The method was used to analyze PAHs contaminated soil/sediment certified reference material CR912 (USEPA). All the measurement fell within the given performance interval.

\subsection{Data analysis techniques}

Statistical treatment of data (principal component analysis) was carried out using the statistical package software of SAS 6.12 licensed to SAS Institute Inc., Cary, NC. For the distribution map, Surface Mapping System (Ver. 7.0, Golden software, CO, USA) was used, and the concentration of PAHs was displayed as contour plot on the sampling map.

\section{Results and discussion}

\subsection{PAHs concentrations in soils}

The concentrations below their limits of detection were given a value of zero for the calculation. The data for individual PAHs and total PAHs are presented in Table 1 and the distribution map of total PAHs content obtained as a contour plot is shown in Fig. 2. The frequency of detection varied from $73 \%$ for $\mathrm{BaA}$ to $100 \%$ for BaP. The median concentration of 8 Car-PAHs in this study was 0.141 in rural soils and $0.405 \mu \mathrm{g} \mathrm{g}^{-1}$ in suburban soils, falling in the concentration range between rural and urban areas (Menzie et al., 1992). However, it was notable that $\mathrm{BaP}$, the most potent carcinogenic PAHs, was $0.005-0.270 \mu^{g^{-1}}$ with a mean of $0.055 \mu \mathrm{g} \mathrm{g}^{-1}$, which was even higher than those in the industrial areas $\left(0.17-6.03 \mu \mathrm{g} \mathrm{g}^{-1}\right)$ and commercial areas $\left(0.09-4.19 \mu \mathrm{g} \mathrm{g}^{-1}\right)$ in Tokyo (Matsushita et al., 1980) and in the city of Chiang-Mai, Thailand $\left(0.022 \mu \mathrm{g} \mathrm{g}^{-1}\right.$; Amagai et al., 1999).

The sum of 16 priority PAHs ( $\sum$ EPA-PAHs) ranged over two orders of magnitude from 0.016 at rural sample 1 to $3.884 \mu \mathrm{g} \mathrm{g}^{-1}$ at suburban sample 40 . The mean content of total PAHs for all samples collected was $1.347 \mu \mathrm{g} \mathrm{g}^{-1}$ with the relative standard deviation of 
Table 1

The concentrations ( $\mu \mathrm{g} \mathrm{g}^{-1}$, dried weight) of individual PAHs in soils on the outskirts of Beijing

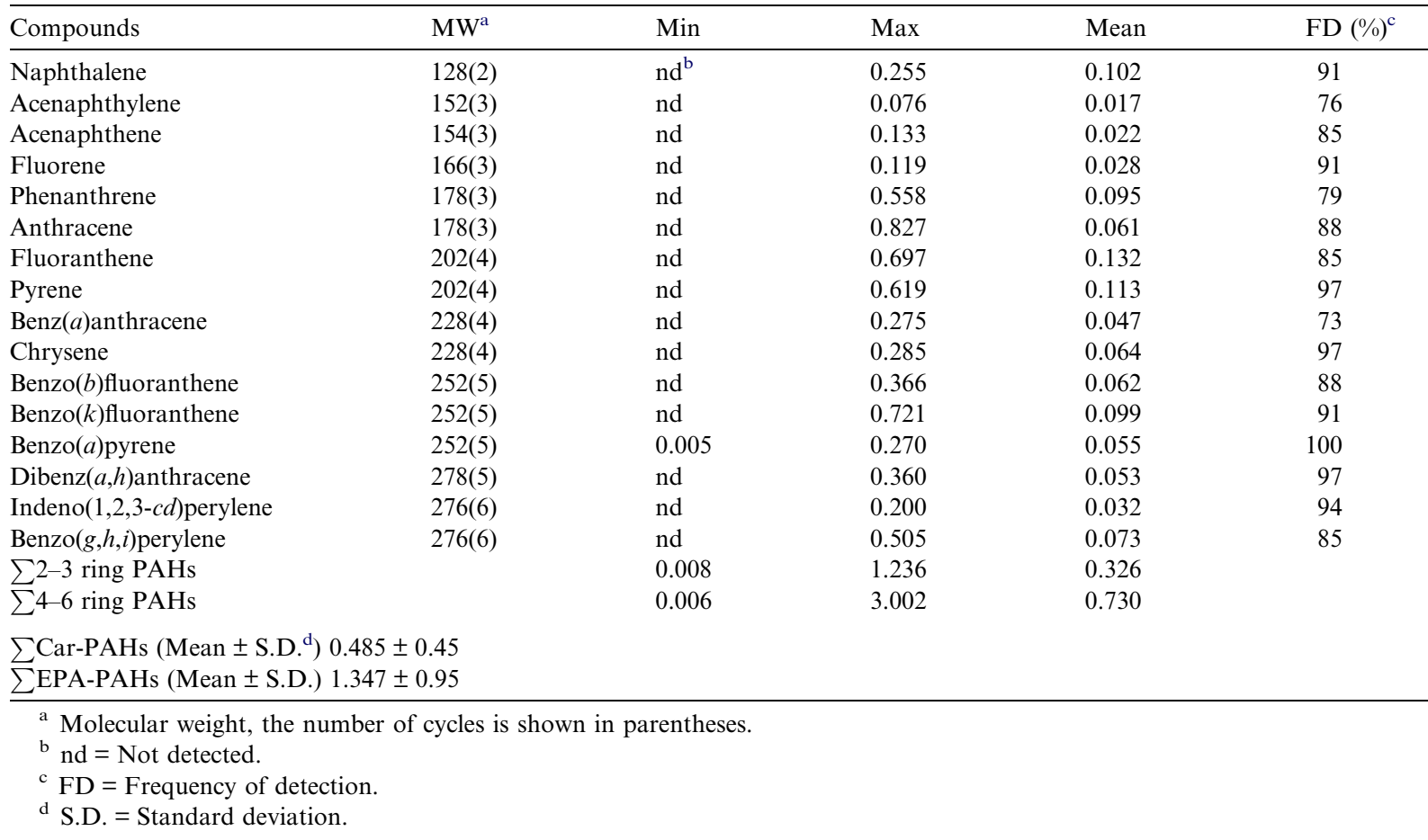

$70.5 \%$, suggesting the significant spatial difference. The concentrations in rural samples except for sample 13 (2.146 $\left.\mu \mathrm{g} \mathrm{g}^{-1}\right)$ were all less than $1 \mu \mathrm{g} \mathrm{g}^{-1}$ with the median of $0.345 \mu \mathrm{g} \mathrm{g}^{-1}$, which was higher than those presented in rural soils in United Kingdom, the median value of which was $0.187 \mu \mathrm{gg}^{-1}$ (Wild and Jones, 1995) and in South Korea, the median value of which was $0.236 \mu \mathrm{g} \mathrm{g}^{-1}$ (Nam et al., 2003). It was reported that the levels of PAHs in soils in urban areas were approximately a factor of 2-10 higher than those in rural areas (Lodovici et al., 1994; Tremolada et al., 1996; Wagrowski and Hites, 1997). The mean PAHs contamination level here $\left(1.308 \mu \mathrm{g} \mathrm{g}^{-1}\right)$ in suburban soils was 2.8 times higher than that in the rural area $\left(0.464 \mu \mathrm{g} \mathrm{g}^{-1}\right)$. Three areas with concentrations above $3 \mu \mathrm{g} \mathrm{g}^{-1}$ were all in the suburban areas. The spatial variation may be accounted for by the fact that there are more PAHs inputs in suburban areas due to the large number of vehicles and types of industry than in the rural areas. As reported, the ratio of motor vehicles in urban, suburban and remote urban was 150:16:1 (Chen, 1995). PAHs are usually present in the particulate matter (Okuda et al., 2002). The weekly average $\mathrm{PM}_{10}$ (particulate matter less than $10 \mu \mathrm{m}$ ) mass concentration at the Ming Tombs area, around $40 \mathrm{~km}$ northeast from the northeast from central Beijing, was $119 \mathrm{\mu g} \mathrm{m}^{-3}$ in winter compared to $313 \mu \mathrm{g} \mathrm{m}^{-3}$ at the urban Beijing site, close to the fourth ring road (Shi et al., 2003).
It seems that the surface soils on Beijing outskirts contaminated with PAHs are obviously above the endogenous level (0.001-0.010 $\mathrm{g} \mathrm{g} \mathrm{g}^{-1}$; Edwards, 1983). Most samples in the study were much higher than the target value set by Dutch government for unpolluted soil (0.02-0.05 $\mathrm{mg} \mathrm{g}^{-1}$ dry weight) (Van Brummelen et al., 1996). Generally, in $62 \%$ soils sampled the concentrations of PAHs ranged from 0 to $1 \mu^{g^{-1}}$; in $32 \%$ sample the concentrations fell the range of those of urban background (1-3 $\left.\mu \mathrm{g} \mathrm{g}^{-1}\right)$ in highly industrialized countries (Weiss et al., 1994; Meharg et al., 1998); and in 6\% sample the concentrations were above $3 \mu \mathrm{g} \mathrm{g}^{-1}$, but did not exceed $4 \mu \mathrm{g} \mathrm{g}^{-1}$ - the intervention value set for soil sanitation (Van Brummelen et al., 1996).

\subsection{PAHs profile}

Table 2 shows correlation values $(r)$ among 16 individual EPA-PAHs and $\sum$ PAHs. The compounds of $\mathrm{Pyr}, \mathrm{BaA}, \mathrm{Flu}, \mathrm{BbF}, \mathrm{BaP}, \mathrm{Chr}$ and $\mathrm{Ph}$ gave strong correlation $(r>0.8)$ with soil $\sum$ PAHs values. There was a relatively good correlation $(r>0.5)$ existing among most of the compounds. Such result suggests that the compositions of the major PAHs are fairly constant at different sampling sites and may come from the similar sources.

The average PAHs profiles in rural and in suburban soils are given in the bar diagram (Fig. 3). Except for the compounds of InP and DBA, the contents of other 


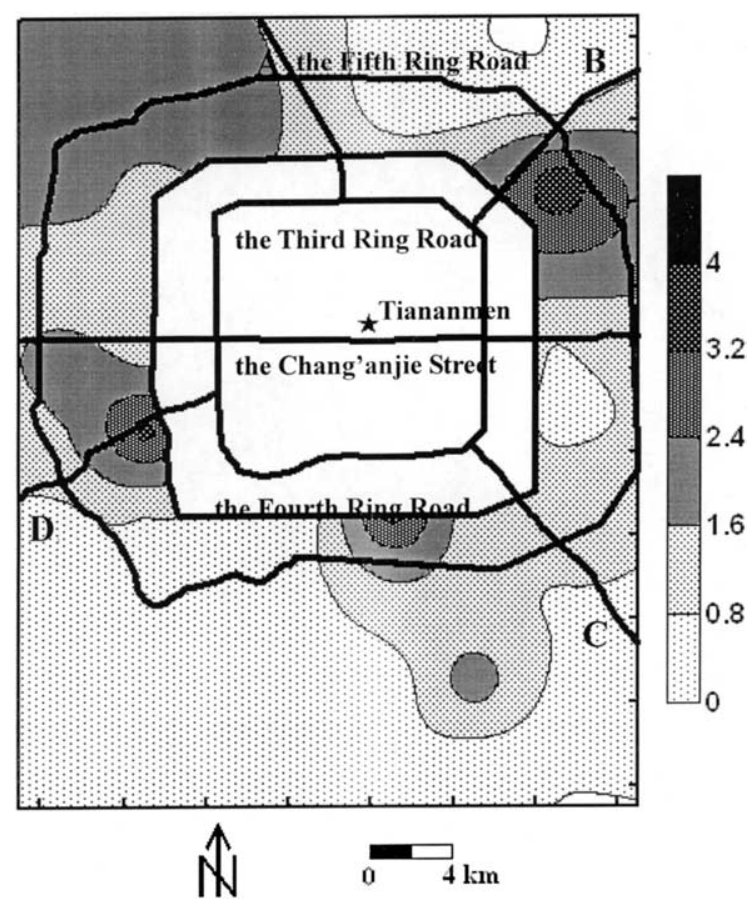

Fig. 2. The contour map of the sum of PAHs $\left(\mu \mathrm{g} \mathrm{g}^{-1}\right.$, dried weight) in soils on the outskirts of Beijing.

PAHs in rural soils were all lower than those in the suburban soils. In suburban soils, PAHs were on average dominated by $\mathrm{Flu}>\mathrm{Pyr}>\mathrm{Ph} \approx \mathrm{BkF} \approx \mathrm{Na}>\mathrm{BghiP}$ in order. This result was similar to those found in typical temperate soils (Jones et al., 1989; Bradley et al., 1994). In the rural soils, $\mathrm{InP}>\mathrm{BkF} \approx \mathrm{Na}>\mathrm{Ph} \approx \mathrm{An} \approx$
DBA were dominated. The similar profiles indicate similar sources of PAHs in both the rural and suburban soils in Beijing.

On average, the compositions of PAHs here were characterized with high molecular weight PAHs that were known to be carcinogenic. The 4-6 ring PAHs represented about $66 \%$ and $70 \%$ of the total EPA-PAHs found in rural and suburban soils, respectively. According to the study of Okuda et al. (2002), automotive exhausts significantly affected PAHs loading to Beijing air. The abundant 4-5 ring compounds were observed in airborne particulate in Beijing (Simoneit et al., 1991). Therefore, the atmospheric depositions most likely contributed to the high molecular weight PAHs found in the soils. In addition, once deposited the low molecular weight PAHs are available to be degraded and desorpted during transportation and easily evaporate to air or leak into deep soil while higher molecular weight PAHs are relatively less loss from the soil (Bossert and Bartha, 1986) and then, the distribution pattern of PAHs in soil tends to shift to the high weight PAHs. However, it was notable that $\mathrm{Na}$, as one relatively volatile and easily degradable $\mathrm{PAH}$, was found at high levels (accounting for $12 \%$ in rural soils and $9 \%$ in suburban soils) in Beijing soils. It was reported that $\mathrm{Na}$ accounted for the majority of the mass in coke oven, highway tunnel, and gasoline engine samples (Khalili et al., 1995).

\subsection{Principal component analysis (PCA) and sources}

To get more insight into the data structure, PCA was performed. Concentrations of 16 EPA-PAHs as active variables and 47 samples as subjects were selected. The

Table 2

Correlation coefficient matrix for soil individual PAHs and the sum of PAHs ( $\left.\sum \mathrm{PAHs}\right)(n=47)$

\begin{tabular}{|c|c|c|c|c|c|c|c|c|c|c|c|c|c|c|c|c|}
\hline & $\mathrm{Na}$ & Acy & Ace & $\mathrm{Fl}$ & $\mathrm{Ph}$ & An & Flu & Pyr & $\mathrm{BaA}$ & Chr & $\mathrm{BbF}$ & $\mathrm{BkF}$ & $\mathrm{BaP}$ & InP & DBA & BghiP \\
\hline \multicolumn{17}{|l|}{$\mathrm{Na}$} \\
\hline Acy & .842 & & & & & & & & & & & & & & & \\
\hline Ace & .524 & .534 & & & & & & & & & & & & & & \\
\hline $\mathrm{Fl}$ & .467 & .539 & .874 & & & & & & & & & & & & & \\
\hline $\mathrm{Ph}$ & .652 & .744 & .648 & .683 & & & & & & & & & & & & \\
\hline An & -.083 & -.017 & .559 & .545 & -.001 & & & & & & & & & & & \\
\hline Flu & .611 & .722 & .504 & .564 & .888 & -.035 & & & & & & & & & & \\
\hline Pyr & .620 & .812 & .536 & .548 & .861 & .023 & .927 & & & & & & & & & \\
\hline $\mathrm{BaA}$ & .509 & .653 & .496 & .545 & .788 & .008 & .946 & .899 & & & & & & & & \\
\hline $\mathrm{Chr}$ & .496 & .554 & .678 & .661 & .732 & .248 & .869 & .805 & .889 & & & & & & & \\
\hline $\mathrm{BbF}$ & .556 & .799 & .422 & .475 & .719 & -.001 & .817 & .900 & .863 & .658 & & & & & & \\
\hline $\mathrm{BkF}$ & .007 & .181 & .429 & .386 & .181 & .596 & .214 & .290 & .299 & .343 & .341 & & & & & \\
\hline $\mathrm{BaP}$ & .568 & .765 & .474 & .475 & .739 & -.015 & .820 & .858 & .863 & .679 & .912 & .356 & & & & \\
\hline $\mathrm{InP}$ & .078 & .109 & .082 & -.013 & .135 & -.095 & .143 & .196 & .193 & .086 & .243 & .000 & .277 & & & \\
\hline DBA & -.062 & .020 & .279 & .072 & -.042 & .292 & -.043 & .070 & .074 & .094 & .167 & .268 & .216 & .198 & & \\
\hline BghiP & .291 & .445 & .131 & .099 & .223 & -.034 & .177 & .378 & .159 & .120 & .393 & .475 & .342 & .023 & .082 & \\
\hline$\sum$ PAHs & .610 & .780 & .710 & .702 & .834 & .276 & .876 & .926 & .879 & .845 & .873 & .554 & .870 & .225 & .199 & .429 \\
\hline
\end{tabular}




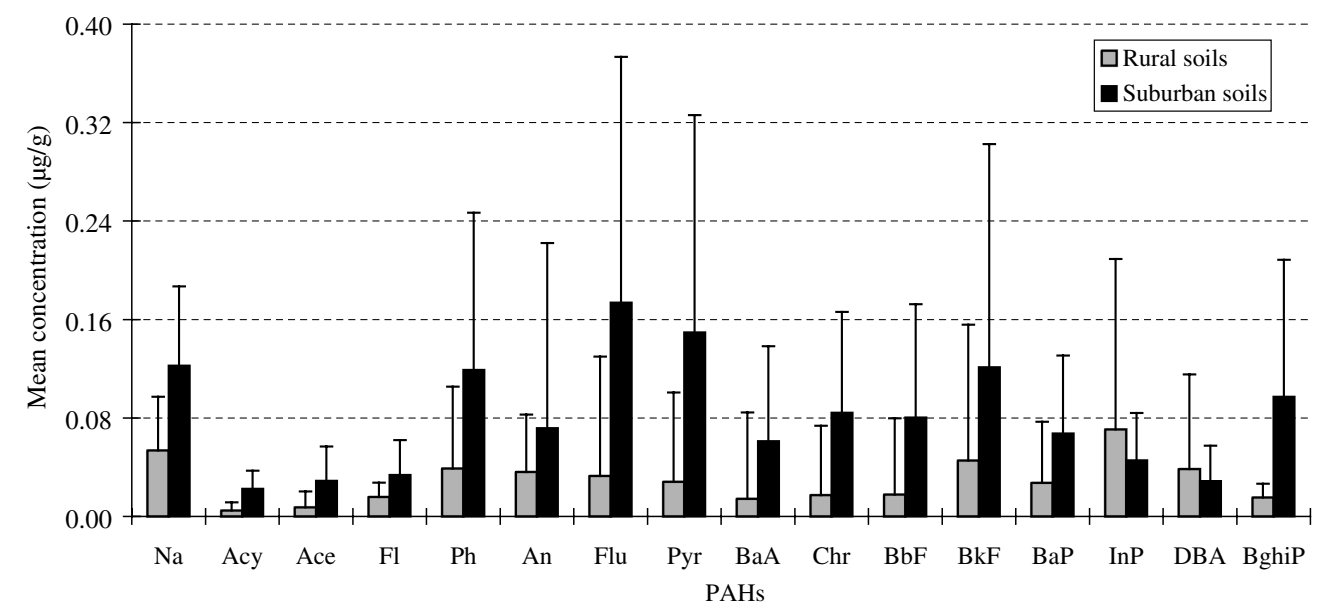

Fig. 3. The mean concentration of the individual PAHs in rural and suburban soils in Beijing. Bars represent means and vertical lines represent standard deviations, respectively.

majority of the variance $(82.07 \%)$ of the scaled data was explained by four eigenvectors-principal components. The first principal component (PC1) explained 51.54\%. The second (PC2), the third (PC3) and the fourth (PC4) principal component explained 13.95\%, 9.06\% and $7.52 \%$ of the total variances, respectively.

Fig. 4 shows the loadings for the individual PAHs on the principal component plane (PC1 vs PC2). Along the axis $\mathrm{PC} 1$, all the compounds were found on the positivecoordinate side and no one on the negative-coordinate side. PC1 had a strong significant correlation with Pyr,

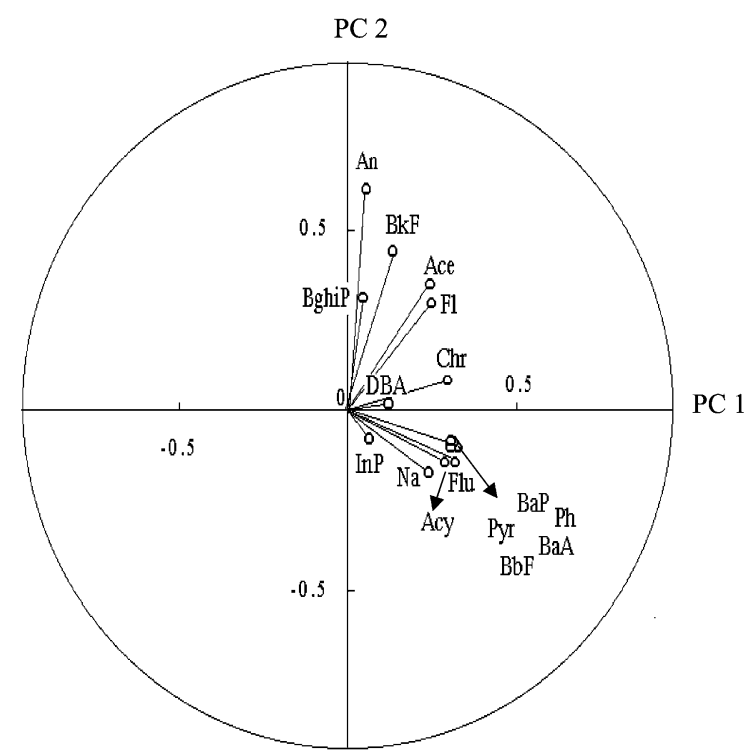

Fig. 4. Principal component plot (PC1 vs PC2) for comparison of the PAHs profiles: loadings for the individual PAHs.
Flu, BaA, Ph, BbF, BaP and Chr. As displayed in Table 2 , these compounds gave strong correlation with the total PAHs concentration $(r>0.8)$. Thus, PC1 is a quantitative correlation component and corresponds to the total PAHs concentration. The compounds of $\mathrm{Pyr}, \mathrm{Ph}$ and $\mathrm{BbF}$ are components of fossil fuels and a portion of them is associated with their combustion (Rogge et al., 1993a; Kavouras et al., 2001). BaP is usually emitted from catalyst and noncatalyst automobiles (Rogge et al., 1993b,c). BaA and $\mathrm{Chr}$ are often resulted from the combustion of both diesel and natural gas (Rogge et al., 1993a; Khalili et al., 1995). Thus it can be seen, $\mathrm{PC} 1$ reflected the effects of traffic pyrolysis or combustion on the sum of PAHs. PC2 dominated by An, $\mathrm{BkF}$, Ace and BghiP. PC3 and PC4 were characterized by high loadings of InP, BghiP and DBA, which were also associated with traffic emission (Baek et al., 1991; Li and Kamens, 1993; Fraser et al., 1997).

Although the distribution of remained PAHs in soil is related to soil property, PAHs have significant variation in their composition for different combustion sources. Therefore, the characteristic spectrum of PAHs could be used as fingerprint to identify their sources (Khalili et al., 1995). The composition of PAHs in the soils on Beijing outskirts was characterized with heavy PAHs, which was considered as combustion origin products (Masclet et al., 1987; Budzenski et al., 1997). The ratio of the sum of major combustion specific compounds ( $\sum$ COMB, Flu, Pyr, BaA, Chr, BbF, $\mathrm{BkF}, \mathrm{BaP}, \mathrm{InP}$ and BghiP) to the sum of 16 EPA-PAHs ( $\left.\sum \mathrm{COMB} / \sum E P A-P A H s\right)$ was averagely 0.5 in rural and 0.6 in suburban areas, which further indicated that extensive combustion activities affected the PAHs in Beijing soils.

To corroborate the above conclusions, the ratios of $\mathrm{Ph} / \mathrm{An}$ and Flu/Pyr were calculated. These ratios have 


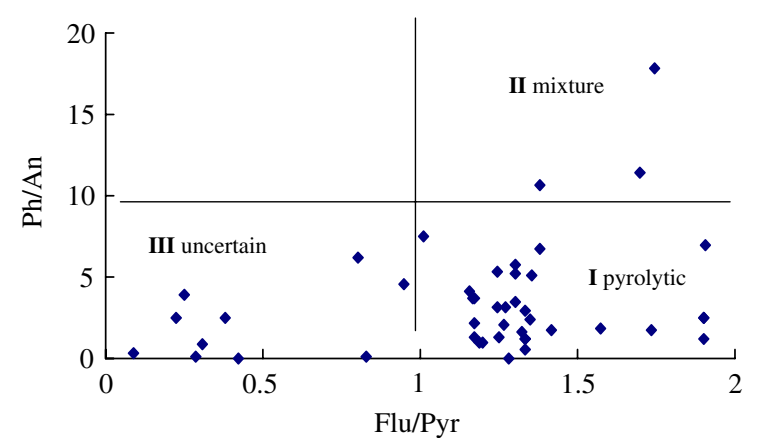

Fig. 5. Cross plot of fluoranthene/pyrene (Flu/Pyr) vs phenanthrene/anthracene $(\mathrm{Ph} / \mathrm{An})$ ratios in soils on Beijing outskirts.

been used extensively to distinguish petrogenic and pyrogenic sources of PAHs. A $\mathrm{Ph} / \mathrm{An}$ ratio of less than 10 and Flu/Pyr ratio of greater than 1 suggest strong pyrogenic origins of PAHs (Baumard et al., 1998). Cross plot analysis (Fig. 5) showed that $94 \%$ of samples fell in the pyrogenic zone (I). There were three samples with $\mathrm{Ph} / \mathrm{An}>10$ while Flu/Pyr $>1$ indicated the mixture (II) of pyrogenic and petrogenic sources of PAHs. Ten samples (III) with $\mathrm{Ph} / \mathrm{An}<10$ but Flu/Pyr $<1$ were excluded from the two categories, for which it was difficult to verify the PAHs from various pollution sources just by the selected ratios.

\section{Conclusions}

1. The investigation showed soils on Beijing outskirts contaminated with PAHs were obviously above the nature level. The PAHs concentrations in the suburban area were higher than those in the rural area and there were similar PAHs profiles between them indicating similar sources.

2. Generally, the compositions of PAHs in outskirts soils were characterized with high molecular weight $\mathrm{PAHs}$ and the mean concentration of $\mathrm{BaP}$ was even higher than that in the urban areas of the developed countries.

3. The results of a principal component analysis together with the concentrations of selected marked compounds and the special PAHs compound ratios displayed the importance of combustion, especially the traffic emission, on PAHs in soils.

\section{Acknowledgments}

Major State Basic Research Program of China (G1999045707) and KIP of CAS (RCEES 9902/9906) supported the investigation. The authors are greatly grateful to Dr. D.R. Zhang for doing in the experiment.
We also thank Agilent Technologies Co. Ltd (China) for GC-MS analysis supporting.

\section{References}

Amagai, T., Takahashi, Y., Matsushita, H., Morknoy, D., Sukasem, P., Tabucanon, M., 1999. A survey on polycyclic aromatic hydrocarbon concentrations in soil in ChiangMai, Thailand. Environ. Int. 25, 563-572.

Baek, S.O., Field, R.A., Goldstone, M.E., Kirk, P.W., Lester, J.N., Perry, R., 1991. A review of atmospheric polycyclic aromatic hydrocarbons: sources, fate, and behavior. Water Air Soil Pollut. 60, 279-300.

Baumard, P., Budzinski, H., Garrigue, P., 1998. Polycyclic aromatic hydrocarbons in sediments and mussels of the western Mediterranean Sea. Environ. Toxiocol. Chem. 17, 765-776.

Bi, X.H., Chu, S.G., Xu, X.B., 2001. Polycyclic aromatic hydrocarbons and polychlorinated biphenyl contamination in DaTong City, China. Bull. Environ. Contam. Toxicol. 67, 141-148.

Bispo, A., Jourdain, M.J., Jauzein, M., 1999. Toxicity and genotoxicity of industrial soils polluted by polycyclic aromatic hydrocarbons (PAHs). Org. Geochem. 30, 947-952.

Bossert, I.P., Bartha, R., 1986. Structure-biodegradability relationships of polycyclic aromatic hydrocarbons in soil. Bull. Environ. Contam. Toxicol. 37, 490-495.

Bradley, L.J.N., Magee, B.H., Allen, S.L., 1994. Background levels of polycyclic aromatic hydrocarbons (PAHs) and selected metals in New England urban soils. J. Soil Contam. 3, 349-361.

Budzenski, H., Jones, I., Bellocq, J., Pierad, C., Garrigues, P., 1997. Evaluation of sediment contamination by polycyclic aromatic hydrocarbons in the Gironde estuary. Mar. Chem. 58, 85-97.

Chen, X., 1995. The traffic artery in Beijing is rapidly exacerbating. Beijing Daily, October 17.

Chu, S.G., Liu, H., Ma, L.L., Xu, X.B., 2003. Polycyclic aromatic hydrocarbons in soil adjacent to highways in Beijing, People's Republic of China. Bull. Environ. Contam. Toxicol. 70, 972-977.

Cousins, I.T., Beck, A.J., Jones, K.C., 1999. A review of the processes involved in the exchange of semi-volatile organic compounds (SVOC) across the air-soil interface. Sci. Total Environ. 228, 5-24.

Edwards, N.T.J., 1983. Polycyclic aromatic hydrocarbons (PAHs) in the terrestrial environment - a review. J. Environ. Qual. 12, 427-441.

Fraser, M.P., Cass, G.R., Simoneit, B.R.T., Rasmussen, R.A., 1997. Air quality model evaluation data for organics. 4. $C_{2}-$ $\mathrm{C}_{36}$ non-aromatic hydrocarbons. Environ. Sci. Technol. 31, 2356-2367.

He, K., Yang, F., Ma, Y., Zhang, Q., Yao, X., Chan, C., Cadle, S., Chan, T., Mulawa, P., 2001. The characteristics of $\mathrm{PM}_{2.5}$ in Beijing, China. Atmos. Environ. 35, 4959-4970.

IARC (International Agency for Research on Cancer), 1983. IARC monographs on the evaluation of the carcinogenic risk of chemicals to human. Polynuclear aromatic compounds, Part I, Chemical, environmental, and 
experimental data. World Health Organization, Geneva, Switzerland.

Jones, K.C., Stratford, J.A., Waterhouse, K.S., Vogt, N.B., 1989. Organic contaminants in Welsh soils: polynuclear aromatic hydrocarbons. Environ. Sci. Technol. 23, 540-550.

Katagiri, M.A.K., Tamura, K., Yamamoto, S., Matsumoto, M., Li, Y.F., Cao, S.R., Ji, R.D., Liang, C.K., 1996. Indoor and outdoor air pollution in Tokyo and Beijing supercities. Atmos. Environ. 30, 695-702.

Kavouras, I.G., Koutrakis, P., Tsapakis, M., Lagoudari, E., Stephanou, E.G., Baer, D.V., Oyola, P., 2001. Source apportionment of urban particulate aliphatic and polynuclear aromatic hydrocarbons (PAHs) using multivariate methods. Environ. Sci. Technol. 35, 2288-2294.

Khalili, N.R., Scheff, P.A., Holsen, T.M., 1995. PAH source fingerprints for coke ovens, diesel and gasoline engines, highway tunnels, and wood combustion emissions. Atmos. Environ. 29, 533-542.

Kipopoulou, A.M., Manoli, E., Samara, C., 1999. Bioconcentration of polycyclic aromatic hydrocarbons I vegetables grown in an industrial area. Environ. Pollut. 106, 369-380.

Li, C.K., Kamens, R.M., 1993. The use of polycyclic aromatic hydrocarbons as source signatures in receptor modeling. Atmos. Environ. 27A, 523-532.

Li, R.Q., Zhang, Z.Q., Shi, J.H., Liu, X.D., Yu, T., 2001. The analysis of organic compounds of atmospheric aerosols in Beijing. Res. Environ. Sci. 14, 21-23, and 28.

Liu, M., Baugh, P.J., Hutchinson, S.M., Yu, L., Xu, S., 2000. Historical record and sources of polycyclic aromatic hydrocarbons in core sediments from the Yangtze Estuary, China. Environ. Pollut. 110, 357-365.

Lodovici, M., Dolara, P., Taiti, S., Carmine, P.D., Bernard, L., Agati, L., Ciappellano, S., 1994. Polynuclear aromatic hydrocarbons in the leaves of the evergreen tree (Laurus nobilis). Sci. Total Environ. 153, 61-68.

Ma, L.L., Chu, S.G., Xu, X.B., 2003. Organic contamination in the greenhouse soils from Beijing suburbs, China. J. Environ. Monit. 5, 786-790.

Masclet, P., Bresson, M.A., Mouvier, G., 1987. Polycyclic aromatic hydrocarbons emitted by power stations, and influence of combustion conditions. Fuel 66, 556-562.

Matsushita, H., Kato, Y., Hisamatsu, Y., 1980. Distribution of benzo $(a)$ pyrene content in soil in urban area. J. Jpn. Soc. Air Pollut. 15, 348-352.

Meharg, A.A., Wright, J., Dyke, H., Osborn, D., 1998. Polycyclic aromatic hydrocarbon (PAH) dispersion and deposition to vegetation and soil following a large scale chemical fire. Environ. Pollut. 99, 29-36.

Menzie, C.A., Potocki, B.B., Santodonato, J., 1992. Exposure to carcinogenic PAHs in the environment. Environ. Sci. Technol. 26, 1278-1284.

Nam, J.J., Song, B.H., Eom, K.C., Lee, S.H., Smith, A., 2003. Distribution of polycyclic aromatic hydrocarbons in agricultural soils in South Korea. Chemosphere 50, 1281-1289.

Okuda, T., Kumata, H., Naraoka, H., Takada, H., 2002. Origin of atmospheric polycyclic aromatic hydrocarbons (PAHs) in Chinese cities solved by compound-specific stable carbon isotopic analyses. Org. Geochem. 33, 1737-1745.

Perera, F.P., 1997. Environment and cancer: who are susceptible? Science 278, 1068-1073.
Rogge, W.F., Hildemann, L.M., Mazurek, M.A., Cass, G.R., Simoneit, B.R.T., 1993a. Sources of fine organic aerosol 2. Noncatalyst and catalyst-equipped automobiles and heavyduty diesel trucks. Environ. Sci. Technol. 27, 636-651.

Rogge, W.F., Hildemann, L.M., Mazurek, M.A., Cass, G.R., Simoneit, B.R.T., 1993b. Sources of fine organic aerosol 4. Particulate abrasion products from leaf surfaces of urban plants. Environ. Sci. Technol. 27, 2700-2711.

Rogge, W.F., Hildemann, L.M., Mazurek, M.A., Cass, G.R., Simoneit, B.R.T., 1993c. Sources of fine organic aerosol 3. Road dust, tire debris, and organometallic brake lining dust: roads as sources and sinks. Environ. Sci. Technol. 27, 18921904.

Shi, Z., Shao, L., Jones, T.P., Whittaker, A.G., Lu, S., Bérubé, K.A., He, T., Richards, R.J., 2003. Characterization of airborne individual particles collected in an urban area, a satellite city and a clean air area in Beijing, 2001. Atmos. Environ. 37, 4097-4108.

Simoneit, B.R.T., Sheng, G., Chen, X., Fu, J., Zhang, J., 1991. Molecular marker study of extractable organic matter in aerosols from urban of China. Atmos. Environ. 25A, 21112129.

Tao, S., Cui, Y.H., Xu, F.L., Li, B.G., Cao, J., Liu, W.X., Schmitt, G., Wang, X.J., Shen, W.R., Qing, B.P., Sun, R., 2004. Polycyclic aromatic hydrocarbons (PAHs) in agricultural soil and vegetables from Tianjin. Sci. Total Environ. 320, 11-24.

Tremolada, P., Burnett, V., Calamari, D., Jones, K.C., 1996. Spatial distribution of PAHs in the UK atmosphere using pine needles. Environ. Sci. Technol. 30, 3570-3577.

Van Brummelen, T.C., Verweij, R.A., Wedzinga, S.A., Van Gestel, C.A.M., 1996. Enrichment of polycyclic aromatic hydrocarbons in forest soil near a blast furnace plant. Chemosphere 32, 293-314.

Van Metre, P.C., Mahler, R.J., Furlong, E.T., 2000. Urban sprawl leaves its PAH signature. Environ. Sci. Technol. 34, 4064-4070.

Wagrowski, D.M., Hites, R.A., 1997. Polycyclic aromatic hydrocarbon accumulation in urban, suburban, and rural vegetation. Environ. Toxicol. Chem. 31, 279-288.

Wang, X.T., Chu, S.G., Ma, L.L., Sun, Y.Z., Li, X.H., Xu, X.B., 2004. Contamination of priority polycyclic aromatic hydrocarbons in water from Guanting reservoir and the Yongding river, China. Bull. Environ. Contam. Toxicol. 72, 194-201.

Wang, X.J., Ren, L.R., Dai, Y.N., Chen, J., Piao, X.Y., Tao, S., 2003. Contents of PAH compounds in different types of soils in Tianjin area. Geograph. Res. 22, 360-366.

Weiss, P., Riss, A., Gschmeidler, E., Schentz, H., 1994. Investigation of heavy metal, PAHs, PCB patters and $\mathrm{PCDD} / \mathrm{F}$ profiles of soil samples from an industrialized urban area (Linz, Upper Austria) with multivariate statistical methods. Chemosphere 29, 2223-2236.

Wilcke, W., 2000. Polycyclic aromatic hydrocarbons (PAHs) in soil-a review. J. Plant Nutr. Soil Sci. 163, 229-248.

Wilcke, W., Müller, S., Kanchanakool, N., Niamskul, C., Zech, W., 1999. Polycyclic aromatic hydrocarbons in hydromorphic soils of the tropical metropolis Bangkok. Geoderma 91, 297-309.

Wild, S.R., Jones, K.C., 1995. Polynuclear aromatic hydrocarbons in the United Kingdom environment: a prelimi- 
nary source inventory and budget. Environ. Pollut. 88, 91-108.

Wild, S.R., Waterhouse, K.S., McGrath, S.P., Jones, K.C., 1990. Organic contaminants in an agricultural soil with a known history of sewage sludge amendments: polycyclic aromatic hydrocarbons. Environ. Sci. Technol. 24, 1706-1711.
Wu, Y., Zhang, J., Zhu, Z., 2003. Polycyclic aromatic hydrocarbons in the sediments of the Yalujiang Estuary, North China. Mar. Pollut. Bull. 46, 619-625.

Yang, G.-P., 2000. Polycyclic aromatic hydrocarbons in the sediments of the South China Sea. Environ. Pollut. 108, 163-171. 